\title{
História fabricada: controvérsias em torno da fundação da cidade de Campinas
}

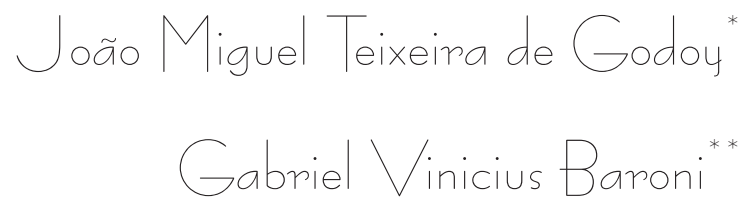

1. Introdução

A escrita da história de muitas cidades paulistas, sobretudo daquelas que surgiram e se consolidaram durante o século XIX nas áreas e regiões onde se estabeleceram as lavouras de café, foi elaborada ou assumiu contornos mais precisos entre os anos 50 e 70 do século XX. Coincidência importante, uma vez que nesse periodo muitas delas como Ribeirão Preto, Piracicaba, Rio Claro e principalmente Campinas - se envolveram (ou foram envolvidas) num processo de reestruturação da economia nacional. Reestruturação essa que ocorreu em escala geral e impactou, sobretudo, a região sudeste - com destaque para o estado e a cidade de São Paulo, que assumiram a posição de pólo dinâmico do processo. Quase como um padrão, esse contexto de mudanças desencadeou nessas cidades, já endurecidas por certo tradicionalismo, todo um esforço de reconstrução do passado, de fixação de uma imagem e de uma identidade. que, no geral, expressavam muito das visões e concepções de uma elite de extração agrária, que nesse momento via-se ameaçada pelas transformações em curso.

\footnotetext{
* Bacharel e licenciado em História pela Universidade de São Paulo (USP) e doutor em História Econômica pela mesma instituição. Professor titular da Faculdade de História da PUC-Campinas. E-mail: joaomigueltgo@yahoo.com.br.

** Aluno concluinte da Faculdade de História da PUC-Campinas e do Programa de Iniciação Científica da mesma instituição. E-mail: gabrielvbaroni@gmail.com.
} 
A história das cidades paulistas, da própria capital São Paulo, das cidades da zona central e do chamado Oeste Paulista, foi escrita, portanto, num momento anterior à consolidação da historiografia acadêmica no Brasil. Foi escrita por autodidatas, e compõe um conjunto de narrativas com características híbridas, onde gêneros diversos se misturam. Memórias pessoais, crônica histórica, jornalismo retrospectivo, obras que incorporam elementos da erudição, muitas vezes influenciadas pelo modelo de historiografia desenvolvido nos institutos históricos e geográficos, academias de letras, etc. Apesar da diversidade de origem de seus autores e dos gêneros, uma estrutura comum e características se repetem, podendo ser facilmente identificadas no conjunto dos escritos sobre as diversas cidades. Em primeiro lugar, uma concepção de progresso que se aproxima do sentimento e da crença religiosa; a ritualização do passado; a articulação sempre oportunista entre tradição e modernidade; a presença intermitente de um espírito de iniciativa das elites; a busca do pioneirismo; o fetichismo do documento articulado paradoxalmente com a afirmação da relação afetiva com o passado como critério de reconstituição; a construção dos mitos fundadores concretizada na obsessão pela data exata da fundação da cidade; a preocupação com o estabelecimento de marcas urbanas dessa visão da história: a nomeação de ruas e praças, a iconografia da cidade, a política de preservação do patrimônio arquitetônico, etc.

O presente trabalho elegeu uma dessas características. Aquela que pareceu-nos trazer uma maior carga de controvérsias e emotividade, ou seja, o problema do estabelecimento da data exata de fundação da cidade. Por mais bizantina que tal discussão possa parecer de início, na verdade ela aponta para características importantes das concepções tradicionais que marcaram, e ainda marcam, as relações de poder no âmbito municipal no Brasil como um todo. Trata-se da relação sempre presente entre o problema da legitimidade do mando com o estabelecimento das genealogias político-familiares e com a questão da longevidade daqueles que habitam tal localidade. Articulam-se nesse contexto a 
questão das linhagens familiares, a ancestralidade telúrica, a tradição, a estabilidade, os esquemas consagrados, o direito legitimo ao poder.

O artigo está estruturado da seguinte maneira: inicialmente, propomos um relato sucinto dos principais eventos relacionados ao processo de surgimento da cidade, que direta ou indiretamente integraram os escritos dos estudiosos da mesma no debate sobre a sua fundação. Em seguida, reconstituímos o debate destacando a postura que os estudiosos tomaram frente a ele. Após isso, tecemos alguns comentários no sentido de identificar as concepções presentes apontando novas possibilidades de abordagem da história. Por fim, retomamos o problema inicial à luz dessa nova abordagem.

\section{A ocupação da região: os dados da experiência}

As origens históricas da ocupação da região onde hoje se encontra Campinas vêm do início do século XVIII, com a abertura do caminho para as minas de Goiás (a chamada "Estrada dos Goiases"), mais especificamente a trilha percorrida pelo segundo Anhanguera entre 1722 e 1725, ocupando a região entre a Vila de Nossa Senhora do Desterro de Jundiaí e Mogi das Cruzes. Nessa região seria concedida pela primeira vez uma sesmaria a Antônio da Cunha Abreu, em 1728. Porém, a mesma apenas seria efetivada em 15 de novembro de 1732 com uma segunda concessão da sesmaria novamente a Antônio da Cunha Abreu e ao seu concunhado. Ainda seriam concedidas sesmarias em 12 de outubro de 1737, em 15 de fevereiro de 1754 e em 16 de julho de 1788 a outros sesmeiros. As várias concessões de sesmarias mostram que a área, ainda nessa ocasião bairro do Mato Grosso de Jundiaí, tornava-se paulatinamente ocupada, transformando-se numa região de roças de subsistência, em função do grande número de aventureiros que se dirigiram às minas e utilizavam a região como trajeto e parada para abastecimento, na qual muitos acabavam por fixar moradia. 
Esse primeiro período da ocupação do território em que hoje se encontra Campinas pode ser definido como um periodo de "bairro rural". Podemos definir esse bairro rural como um habitat disperso, no qual predominavam as culturas de subsistência e famílias conjugais autônomas e autárquicas, mas que mesmo assim possuía contornos suficientemente consistentes para dar noções de pertencimento a certa localidade. ${ }^{1}$

O segundo momento da história da região foi aquele diretamente afetado pelas Políticas Pombalinas. O governo pombalino destacou-se por iniciativas importantes no sentido de fortalecimento do poder do Estado Português contra alguns interesses do catolicismo jesuítico, bem como de alguns setores da nobreza. Além disso, buscou articular uma politica mercantilista externa com reformas internas econômicas e sociais. O Brasil assumiria papel fundamental nessa política, principalmente definindo a formação de monopólios em beneficio da emergência e fortalecimento de companhias manufatureiras na Metrópole. ${ }^{2}$

A politica pombalina, entre outros desdobramentos, estimulou o surgimento de várias povoações, freguesias e elevação de vilas na Capitania de São Paulo. A obra estratégica e geopolítica de ocupação do território paulista foi atribuída a Morgado Mateus, ${ }^{3}$ que delinearia uma nova dimensão para a pequena rede de povoações e vilas existentes na época, adequando-as ao circuito mercantil interno do eixo centro-sul da Colônia, parte fundamental da politica mercantilista pombalina. A função da criação desses povoamentos dizia respeito à criação de obstáculos a qualquer possibilidade de avanço espanhol pela fronteira sudoeste ou então através da

\footnotetext{
${ }^{1}$ Ver QUEIROZ, Maria Isaura Pereira de. Bairros Paulistas: dinâmica das Relações Bairro Rural - Cidade. São Paulo: Ed. Duas Cidades, 1973.

${ }^{2}$ Ver principalmente FALCON, Francisco Calazans. A Época Pombalina. São Paulo: Ática, 1982.

${ }^{3}$ Trata-se de Luís Antônio de Sousa Botelho Mourão, primeiro governador da Capitania de São Paulo recriada por ele mesmo em 1765, onde fundou várias vilas visando a recuperação da capitania. Ver BELLOTO, Heloísa Liberalli. Autoridade e conflito no Brasil Colônia. O governo do Morgado de Mateus em São Paulo. São Paulo: Imesp, 1979.
}

122 Revista de História Regional 16(1): 119-153, Verão, 2011 
Costa Atlântica, protegendo assim a produção aurifera de Minas Gerais e a nova capital, o Rio de Janeiro. ${ }^{4}$

$\mathrm{O}$ até então bairro de Campinas do Mato Grosso de Jundiaí foi elevado à categoria de freguesia em 14 de julho de 1774 por Barreto Leme, que já havia chegado à região em 1739, a pedido de Morgado Mateus, dentro desse contexto de Políticas Pombalinas. Como bem mostra Antônio da Costa Santos:

Com vistas a assegurar fronteiras paulistas com a capitania das Minas Gerais e os domínios do Caminho das Minas dos Goyazes, desenhou-se um arco de ocupação composto por cinco vilas e freguesias, em cujas extremidades ordenaram a fundação de Nossa Senhora da Escada, atual Guararema e Botucatu. Entre estas últimas e sobre esta imaginária figura geométrica, instalou, de modo eqüidistante, São João de Atibaia, elevada para vila, Piracicaba e entre estas duas, exatamente no centro, a Freguesia de Nossa Senhora da Conceição das Campinas do Mato Grosso de Jundiaí, a Única criada sobre a épica estrada goiana, bem no cruzamento com o arco acima citado. ${ }^{5}$

Foi a partir desse período, e em decorrência dessas transformações, que a região central da então Capitania de São Paulo iniciou um novo momento, integrando-se de maneira definitiva nos circuitos da economia internacional. Até então, a região não se encaixava no modelo exportador que caracterizava a colônia. Como bairro de Mato Grosso de Jundiaí, participava como parada dos tropeiros que se dirigiam ao Brasil Central, na região das minas. Porém, o declínio do ciclo do ouro geraria profundas transformações na economia da região, com impactos diretos em sua estrutura social. Os antigos ocupantes, roceiros e pequenos sitiantes, seriam gradativamente substituídos por grandes proprietários organizadores de uma produção em larga escala de produtos agrícolas de exportação. Primeiramente a cana de açúcar e

${ }^{4}$ SANTOS, Antônio da Costa. Campinas das origens ao futuro: Compra e venda de terra e água e um tombamento na primeira sesmaria da Freguesia de Nossa Senhora da Conceição das Campinas do Mato Grosso de Jundiaí (1739-1992). Ed. da Unicamp, Campinas: 2002.

${ }^{5}$ Ibidem, p. 67 
depois o café. Isso acarretou certamente toda uma ordem de mudanças profundas nos modos de vida, crescimento populacional, relações sociais, sistemas de produção e dinâmica histórica para a região.

Em resumo, exporemos a partir de agora os principais marcos desse processo e que serão lidos e apropriados pelos estudiosos com o objetivo de definir o estabelecimento da fundação da cidade. O primeiro marco é de 1722, quando é aberto o caminho para minas de Goyaz. A data de 1728, por sua vez, remete à doação da primeira sesmaria da região. Mais tarde, em 1732, temos outro marco: a efetivação da posse da sesmaria de Antônio Cunha Abreu. Por outro lado, 1739 remete à chegada de Barreto Leme a Campinas, vindo de Jundiaí. No ano de 1772 é emitida a autorização pelo vigário de Jundiaí para a construção de uma capela na região. Em 1773, Barreto Leme obtém a efetivação dessa autorização para construção da capela. Já em 27 de maio de 1774 ocorre a nomeação de Barreto Leme como fundador e diretor da futura freguesia por Morgado Mateus. A data de 14 de julho de 1774 marca a elevação do bairro à freguesia e a realização da sua primeira missa. Mais para o final do século temos, em 14 de dezembro de 1797, a autonomia definitiva da região em relação à Jundiaí, sendo elevada à categoria de vila, como Vila de São Carlos. ${ }^{6}$

\section{O debate sobre a fundação: os dados da interpretação.}

O modo como esses eventos foram lidos e interpretados pelos "historiadores" da cidade, sobretudo autodidatas, foi marcado pela preocupação de estabelecer os seus marcos fundadores. Extraiu-se dessa realidade o problema da fundação de Campinas. ${ }^{7}$ A questão é evidenciada quando nota-

\footnotetext{
${ }^{6}$ Apenas em 1842, com a criação do município, o nome Campinas é retomado.

${ }^{7}$ Existe já um trabalho sobre os debates envolvendo o problema da fundação de Campinas, de autoria de Américo B. Vilela. Campinas revisitada: uma história das histórias do bicentenário de Campinas. Campinas: Sinpro Cultural, ano 11, n. 64 , jul. 2006. O mesmo contribuiu no sentido de levantamento das fontes e
}

124 Revista de História Regional 16(1): 119-153, Verão, 2011 
mos que o municipio comemorou seu bicentenário em duas ocasiões diferentes. Ambas curiosamente coincidiram com momentos em que o Brasil passava por regimes ditatoriais: a primeira vez em 1939, durante o Estado Novo, e a segunda em 1974, durante a ditadura militar. Os debates envolvendo o problema da fundação e as preocupações em estabelecer seus marcos ocorreram desde a primeira comemoração, em 1939. Porém, concentraram-se na década de 1960 e 1970, visando a segunda comemoração sobre o bicentenário da cidade. O debate não apenas desenvolveu-se nas publicações dos historiadores autodidatas, em artigos de jornais, ou publicações historiográficas, mas também no âmbito oficial, ou seja, na Câmara Municipal. Apareceu na forma de requerimentos, projetos e leis, etc. Essa documentação oficial, no entanto, apenas reflete o problema inicial da fundação e o debate entre os autodidatas pelas respostas a esse problema e o estabelecimento dos marcos fundadores.

A dimensão política oficial do debate sobre a fundação começa, ainda de maneira muito incipiente e inusitada, a partir do decreto de 11 de julho de 1960, que estabelecia ponto facultativo em todas as repartições públicas ao instituir o dia de 14 de julho de 1774 como a data oficial de fundação da cidade de Campinas. Definia também como personagem central o sesmeiro Barreto Leme, considerado o fundador. Por uma coincidência de datas (especificamente naquele ano comemorava-se o jubileu episcopal de Dom Paulo de Tarso Campos, arcebispo metropolitano de Campinas), decidiu o prefeito em exercício assinar em homenagem ao arcebispo. Sendo assim, promovia-se uma mudança de 1739 para 1774 , contrariando a primeira comemoração do bicentenário que ocorreu em 1939. Dentro da documentação oficial levantada, aquele que mais reflete o conflito da fundação é o requerimento $\mathrm{n}^{\circ} 712 / 62$, de $1^{\circ}$ de agosto de 1962 , redigido pelo vereador Antônio Rodrigues dos Santos Júnior. O

uma primeira tentativa de análise. Entretanto, deve-se reconhecer que o autor não conseguiu ultrapassar o universo de concepções que informam o conjunto das propostas em debate. Nosso propósito aqui não é tomar partido no interior das proposições em choque, mas propor uma análise dos significados do próprio debate em si. 
requerimento intensifica o debate na dimensão institucional, discordando do decreto oficial e propondo a data de 15 de novembro de 1732. Percebemos no requerimento que, a partir de um marco existente no Largo do Rosário (praça central da cidade), um dos estudiosos da história da cidade e um dos maiores opositores à data de 1774, Jolumá Brito, recorrera uma revisão oficial da história da sua fundação:

Existente, no largo do Rosário, o marco relativo à fundação da cidade de Campinas, cuja data está trazendo controvérsias e possivelmente esteja errada. Há, portanto necessidade de uma solução em definitivo.

O historiador campineiro João Batista de Sá, conhecido como Jolumá Brito, afirma que nossa cidade foi fundada em 1739 e não em 1774, como consta no referido marco. Entendemos que a Câmara Municipal deve assumir uma atitude no sentido de esclarecer em definitivo a situação e que seja constituída uma constituição de entendidos na matéria para que conste de fato no citado marco a data certa.

Requeremos seja constituída uma comissão composta dos Srs. João Batista de Sá, Theodoro de Sousa Campos, José de Castro Mendes, Alaor Malta Guimarães e um vereador, a fim de estudarem a matéria, apresentando um relatório com as conclusões finais. ${ }^{8}$

Após o requerimento, foi de fato composta uma comissão que também contava com os nomes mais representativos desse grupo de historiadores locais: Júlio Mariano, Celso Maria de Mello Pupo, Odilon Nogueira de Mattos, Benedito Barbosa Pupo e vereadores integrantes da comissão de Educação e Cultura. Os estudos dessa comissão acabaram por sustentar o veredicto final sobre o problema na dimensão oficial, mas não esgotariam os debates sobre a data exata da fundação. A partir do requerimento podemos perceber que o debate intensificou-se não somente na Câmara Municipal, mas também fora dela, nos jornais da cidade e nas publicações bibliográficas sobre a sua história. De forma crescente

\footnotetext{
${ }^{8}$ Requerimento ${ }^{\circ} 712-62$, biblioteca da Câmara Municipal de Campinas

126 Revista de História Regional 16(1): 119-153, Verão, 2011
} 
os estudiosos da história da cidade posicionavam-se sobre o tema. Infelizmente, parte da documentação oficial foi perdida, como, por exemplo, o projeto de lei $\mathrm{n}^{\circ} 78 / 70$, que sumiu do arquivo da Câmara Municipal de Campinas há muito tempo e não foi localizado. Esse documento poderia trazer esclarecimentos mais precisos sobre a dimensão politica oficial do debate.

Em 13 de abril de 1971, o governo municipal de Campinas toma definitivamente sua posição oficial e estabelece através da lei $n^{\circ} 3.984$ a data oficial da fundação de Campinas como 14 de julho de 1774, assinada pelo prefeito da época, Orestes Quércia, o que levaria inevitavelmente a uma segunda comemoração de seu bicentenário em 1974, três anos depois de a lei ter sido aprovada. Porém, isso não esgotou o debate, que continuou fortemente até o dia da comemoração. Encerradas as celebrações, entretanto, os ânimos se arrefeceram gradativamente.

Como já dito antes, a dimensão política oficial das controvérsias apenas refletia outra dimensão do problema. A questão de fundo nos remete ao modo como naquele momento o passado da cidade começou a ser revisto e, de certa forma, reinventado. Envolvia, portanto, a leitura da realidade histórica pelos estudiosos autodidatas e sua preocupação em estabelecer os marcos fundadores da cidade de Campinas. Suas propostas e posicionamentos serão expostos, sobretudo, pelas publicações em artigos de jornais. O que ocorreu com bastante intensidade nos periódicos de Campinas, como Diário do Povo e Correio Popular, mas também jornais da capital como o Estado de São Paulo. Além da imprensa, algumas obras de natureza historiográfica abordaram o assunto. No conjunto, podemos identificar três tendências nessas publicações. As primeiras seriam aquelas publicadas durante o período da primeira comemoração do bicentenário, em 1939, e tendem a justificar a comemoração e a data de fundação como sendo a chegada de Barreto Leme em 1739 ao local onde hoje se encontra Campinas, conflitando assim com a postura do Instituto Geográfico e Histórico de São Paulo, que 
já defendia a data de $1774 .{ }^{9}$ Desde a primeira comemoração do bicentenário temos o debate envolvendo a data de fundação da cidade, embora nesse primeiro momento com muito menos intensidade.

Nesse primeiro caso, o debate fica concentrado no conflito entre os estudiosos campineiros, jornais da cidade e o Instituto Histórico e Geográfico de São Paulo, que se negava a participar da comemoração de 1939, pois afirmava que Campinas não teria sido fundada na data em que a cidade queria celebrar, 1739, e sim em 1774, quando Morgado Mateus teria criado não só Campinas, mas outras povoações na capitania. O instituto tratava a comemoração como ridícula, conforme demonstra o seguinte artigo de jornal da época.

O parecer da ilustre comissão como que crivou de ridículo os campineiros, ignorantes de seus próprios fatos, e que amantes das festas vistosas inventaram um despautério histórico como o que a ciência e a austeridade do Instituto, em absoluto podem ser convincentes. ${ }^{10}$

Por outro lado, setores da cidade, através da imprensa, assumiam um posicionamento que buscava valorizar a chegada de Barreto Leme na região, junto com outros ocupantes, como mais significativo do que as decisões e decretos legais. Afirmavam ainda que para eles a atitude do instituto era "uma doutrina intolerante e antipatriótica, admitindo que a história brasileira é só que consta como resultado de leis do governo de El-Rey". ${ }^{11}$ Seus argumentos consistiam em afirmar que antes da fundação oficial, resultado da iniciativa do Morgado Mateus com a criação da freguesia, já existia aqui a povoação. As provas dessa realidade poderiam ser encontradas na mudança de Barreto para Jundiaí em 1730, onde viveu por nove anos, fixando-se logo depois onde hoje seria

${ }_{9}^{9}$ Ver FLORENCE, Amador. Municipios paulistas e seus centenários. Progressão colonizadora. In: Revista do Arquivo Municipal, São Paulo, ano 6, volume LXII, p. 179-208, nov.-dez. 1939.

10 Em que ano foi fundada Campinas? Uma transcrição que põe termo à controvérsia que existia. A Gazeta, Campinas, 15 ago. 1939.

${ }^{11}$ Em que ano foi fundada Campinas? Novos esclarecimentos. A atitude do instituto histórico. A Gazeta, Campinas, 18 ago. 1939.

128 Revista de História Regional 16(1): 119-153, Verão, 2011 
Campinas. A outra prova seria a documentação do livro do tombo da freguesia de Nossa Senhora da Conceição, que em 1772 pedia a fundação da freguesia uma vez que em 30 anos passados já haviam falecido dezenas de pessoas. Assim argumentavam: "se em 1772, já faziam 30 anos que moradores de Campinas viviam vida espiritual pobre e mal alimentada, é que pelo menos em 1742 já havia um povoado". ${ }^{12} \mathrm{O}$ conflito entre o que podemos chamar fundação real e fundação oficial $^{13}$ já aparece aqui na primeira comemoração e retorna durante o período da segunda comemoração do bicentenário, em que o debate será retomado com força. Dessa vez, contudo, ele ocorrerá entre os próprios estudiosos da cidade, e não mais entre a cidade e o Instituto Histórico e Geográfico de São Paulo.

A maior parte do debate aconteceu durante o periodo da segunda comemoração do bicentenário, nos anos que antecederam 1974. Principalmente após o requerimento de 1962 e a composição da comissão da Câmara Municipal para estudo da data de fundação. Nesse período, podemos notar as outras duas tendências das respostas dadas pelos autodidatas. Elas se dividem entre as daqueles que defendiam a data de 1774 e as daqueles que se posicionavam contra essa data. Dentre os autores que se posicionaram a favor de 1774 temos principalmente o Celso Maria de Mello Pupo e Benedito Barbosa Pupo. Enquanto do lado contrário a 1774 temos principalmente a participação de Jolumá Brito e José Jorge Antônio.

Benedito Barbosa Pupo foi um dos principais defensores da data de 1774, escrevendo uma série de artigos para o Correio Popular e o Diário do Povo, além de obras sobre o passado da cidade como as crônicas de 8 bananas por um tostão. Seus argumentos priorizam a participação de Morgado Mateus, ao lado de Barreto Leme, sendo Morgado o autor intelectual da fundação. A data de 1774 é a escolhida, por

12 Em que ano foi fundada Campinas? Uma transcrição que põe termo a controvérsia que existia. A Gazeta, Campinas, 15 ago. 1939.

${ }_{13}$ Para utilizarmos aqui de uma distinção que acabou ficando consagrada por Odilon Nogueira de Mattos. 
se tratar do início da vida urbana da ocupação e fundação oficial. Em sua visão é "considerada precisamente como lançamento das bases do núcleo urbano, excluindo qualquer outra conotação". ${ }^{14}$ Em seus argumentos podemos ver a contraposição entre o urbano e o rural. Para esse autor, antes das ações de Morgado de Mateus só existiria na região a vida rural. Também podemos observar a contraposição entre o pouso e a capela. Para o defensor de 1774, seria a capela o embrião da cidade e não o pouso, portanto a fundação estaria firmada a partir da realização da primeira missa. Caso se aceite que a cidade começou de fato pelo pouso, isso acabaria por contrariar as documentações existentes e a participação de Morgado Mateus e Barreto Leme.

Celso Maria de Mello Pupo foi também um dos defensores da data de 1774 que se destacou no debate. Suas propostas e argumentos aparecem em livros como Campinas, seu berço e juventude como base de defesa da comissão de historiadores que escolheram o 14 de julho como data oficial de fundação. Além disso, escreveu vários artigos para o Correio Popular e o Diário do Povo. Primeiramente Celso Maria de Mello Pupo demonstra que não existem argumentos consistentes e documentação para justificar a fundação de Campinas em outra data que não seja a de 1774. Sobre a sesmaria, o autor diz "as concessões de sesmaria em Campinas nada indicam quanto a exploração das mesmas e povoamento local” e, sendo assim, " a simples concessão não prova ter havido exploração de terra concedida, não prova ter havido povoamento". Já sobre a data de 1739, referente à vinda de Barreto Leme para a região, analisando os documentos do tombo da cidade e os documentos pessoais de Barreto Leme, afirma que "Não se conhece documento que autorize afirmar ter havido em Campinas qualquer povoamento de caráter permanente anterior a 1741-44". ${ }^{15}$ Segundo seus cálculos, o próprio Barreto Leme teria chegado aqui entre 1741 e 1745,

${ }_{14}$ PUPO, Benedito Barbosa. Por que 14 de julho. Correio Popular, Campinas, 14 jul. 1972.

${ }^{15}$ PUPO, Celso Maria de Mello. Campinas seu Berço e Juventude. Campinas: Publicação da Academia Campinense de letras, 1969, p.16-17.

130 Revista de História Regional 16(1): 119-153, Verão, 2011 
tornando-se assim o pioneiro da povoação da região, conduzindo junto com ele familia e amigos.

A posição de Celso Maria de Mello Pupo sobre a fundação da cidade é de que ela não é simplesmente documentação, mas também um ato material. Campinas nasce ao invés de ser fundada. O que temos em 1774 é a fundação de Campinas autônoma como instituição política e religiosa, sendo essa a data mais antiga que se deve se perpetuar sem o risco de erro. Com ele também vem a ideia de que 1774 marcou o início da vida urbana e que, antes disso, somente existia na região vida rural. Até 1774 a região encontrava-se numa estagnação vegetativa, sem progresso e sem crescimento. Sua postura diferenciada dos outros estudiosos que defenderiam a data de 1774 é que, para Celso Maria de Mello Pupo, a participação de Morgado Mateus foi questionável, não devendo ser apresentado como fundador. O autor vê em Morgado uma figura cruel e tende a elevar a participação de Barreto Leme, ao mesmo tempo em que inclui a importância de Frei Antônio na fundação. Como podemos observar:

O idealista que por idealismo fundou Campinas foi Francisco Barreto Leme, e o seu criador que por idealismo criou Campinas foi Frei Antônio de Pádua Teixeira; o Morgado de Mateus, por uma orientação recebida da Coroa Portuguesa, aproveitou-se, para isto, do desejo idealístico de Barreto Leme, assim como o Bispo de São Paulo, na sua função Pastoral, dispôs do zelo apostólico de Frei Antônio."16

Conceição de Arruda Toledo, escrevendo ao Correio Popular, se posicionou a favor de 1774. Para ele, a comemoração de 1939 foi uma farsa e afirma que, a seu ver, a grande maioria está de acordo com a data de 14 de julho de 1774, pedindo inclusive que a Câmara desse um basta nesse debate sobre a fundação, antes que a cidade fizesse um papel de ridículo aos olhos dos intelectuais do país. A ênfase de seus argumentos estava nas comemorações dos bicentenários.

${ }_{16}$ PUPO, Celso Maria de Mello. Campinas seu Berço e Juventude. Campinas: Publicação da Academia Campinense de letras, 1969, p. 48. 
Odilon Nogueira de Mattos foi mais um dos estudiosos que se posicionaram a favor de 1774, participando inclusive da comissão de Educação e Cultura da Câmara Municipal. Acabou por escolher a data oficial de fundação da cidade. Sua contribuição ao debate estava no argumento de que há uma diferença entre a fundação real - algo quase sempre impossivel de ser estabelecido com precisão, por derivar de um lento processo de fixação de povoamento - e a fundação oficial, que é firmada por documentação incontestável, já que oficial. Sobre a fundação oficial, entendia que a data mais adequada seria a de 1774 . Outros marcos anteriores, como a concessão da sesmaria ou chegada de Barreto Leme, não seriam validos, já que em um caso "a sesmaria em si não implica em povoamento ou fundação de cidade"17 e no outro "onde resulta igualmente dificil a fixação precisa da data em que teriam chegado Barreto leme e seus companheiros, o que certamente ocorreu ainda na primeira metade do século XVIII". ${ }^{18}$ Sendo assim, a data oficial de fundação seria o 14 de julho de 1774 , entendendo que as outras não lhe seriam opostas, mas sim complementares.

Jolumá Brito foi um dos estudiosos que mais participou do debate. Escritor de vários livros sobre o passado da cidade, escreveu diversos artigos para o Diário do Povo e se tornou um dos principais nomes a se posicionarem contra a data de 1774. Seu principal argumento era o de que não existia nenhum documento escrito confirmando a data de 14 de julho de 1774 como data da fundação de Campinas. Afirma sempre a relação entre história e a documentação escrita. O fetichismo do documento escrito e oficial é a característica mais marcante nos argumentos de Jolumá Brito. Como ele mesmo afirma "e se história é documento. NÃO UM SÓ DELES QUE POSSAM PROVAR que 14 de julho de 1774 seja data oficial documentada para ser ponto de partida da fundação de Campinas". ${ }^{19}$ Para ele, 1774 represen-

\footnotetext{
${ }^{17}$ MATTOS, Odilon Nogueira. A propósito da fundação de Campinas. In: Revista Bibliográfica e histórica, Campinas, n. 19, jan.-fev. 1971.

${ }^{18}$ Ibidem.

${ }^{19}$ Contra 14 de Julho. Diário do Povo, 14 jul.1972.
}

132 Revista de História Regional 16(1): 119-153, Verão, 2011 
taria, sobretudo, a fundação religiosa da cidade e, mesmo assim, a primeira missa não teria sido realizada nessa data, mas em 17 de julho de 1773, praticamente um ano antes. Todavia, antes disso já existiria uma povoação aqui, desde que fora constituído o primeiro pouso em 1732, portanto, desde a confirmação da posse da primeira sesmaria. Seria nessa data a fundação de Campinas, conforme a existência de documentação comprobatória. Sobre o documento de Morgado Mateus para Barreto Leme fundar a freguesia, Jolumá transcreve e destaca o trecho onde se diz: "um mês e dezoito dias depois de fundada Campinas e da nomeação de seu fundador Francisco Barreto Leme. OFICIALMENTE NOS DIAS DE HOJE, a cidade FOI FUNDADA NOVAMENTE." ${ }^{20}$ É a expressão "fundada novamente" que o leva a afirmar já haver Campinas antes de 1774.

Jorge Antônio José foi um dos principais contestadores da data de 1774. Em seus inúmeros artigos ao Correio Popular, suas ideias se voltavam contra a noção de que Morgado Mateus havia sido cofundador da cidade e de que a freguesia seria o primeiro ponto para fundação de Campinas. Para ele, havia dois erros ao instituir-se a data de 1774 como data de fundação. O primeiro seria consagrar uma data inverídica e anular outra, a de 1739, que apesar de também não ser confiável como data certa da fundação da cidade já era uma data escolhida, sendo inclusive realizada uma comemoração baseada nela. Assim, a data de 1739 foi considerada totalmente sem efeito e sequer foi absorvida pela segunda data. A seu ver, a fundação deveria ser definida pelos primeiros fluxos de fixação de povoadores que chegaram à região, mesmo que esses fossem esparsos. Desse modo, a data de 1774 não poderia ser considerada como fundação, pois, como ele mesmo afirma: "quanto à iniludivel existência de um efetivo nucleamento na área, décadas antes dos discutidos dos anos 70 daquele século." ${ }^{21} \mathrm{E}$ afirma ainda que, se pensarmos em ocupação na região durante o século XVIII, podemos afir-

\footnotetext{
${ }^{20}$ BRITO, Jolumá. Sob o Império da Lei. Diário do Povo, 14 jul.1973.

${ }^{21}$ JOSÉ, Jorge Antônio. Campinas não foi fundada em 1774. Correio Popular, Campinas, 18 set. 1974.
} 
mar que "já na terceira década do século XVIII a área estava ocupada, como mandavam as Ordenações do reino e os propósitos da coroa, no acrescentamento da fé e o povoamento cristão". ${ }^{22}$

Para Jorge Antônio José, em 1774 apenas elevou-se a cidade à categoria de freguesia, pois freguesia para ele não passava de uma ordem eclesiástica e não um grupo de frequentadores, como já existia. Porém, não havia autonomia como ordem eclesiástica, já que ela estaria sempre sujeita a Jundiaí. Em 1774, Campinas continuava dependente de Jundiaí, sendo assim, não seria possivel naquele momento fundar uma freguesia com autonomia paroquial e, mesmo que fosse o caso, "não bastaria para que o bairro se desmembrasse de Jundiaí formando um organismo secular, civil com governo próprio que daria aos moradores vida municipal autônoma". ${ }^{23}$ A autonomia civil não dependia da eclesiástica. Já sobre a participação de Morgado Mateus, ele a considera importante, porém entende que não pode ser considerado cofundador da cidade, já que a mesma não foi fundada em 1774. Não fundou nada, na verdade, pois a povoação aqui já existia, e no caso da freguesia não teria poder para fundar uma.

Ataliba Amadeu Sevá, escrevendo para o Diário do Povo e para a Sociedade de Artes, Cultura e Ensino de Campinas, vê a história da cidade ligada aos grandes feitos dos Bandeirantes. Para ele, a fundação teve início a partir do estabelecimento do pouso, antes da freguesia. Sobre a oficialização da data de 1774, escreve que "aceitamo-la, embora, outras datas devam ser rememoradas". ${ }^{24}$ Assim como as datas referentes a 1728, 1739, e 1773. Mas, em seu entendimento, através da documentação existente a data de fundação de Campinas ainda seria a de 1739 e seu início estaria na chamada "Campinas Velha". Nele vemos não apenas a preocu-

\footnotetext{
${ }^{22}$ JOSÉ, Jorge Antônio. Campinas não foi fundada em 1774. Correio Popular, Campinas, 18 set. 1974 .

${ }^{23}$ Ibidem.

${ }^{24}$ Sevá, Ataliba Amadeu. Um pouco da História da Fundação de Campinas.
}

Diário do Povo, Campinas, 31 jul.1974.

134 Revista de História Regional 16(1): 119-153, Verão, 2011 
pação com a definição do marco cronológico da fundação da cidade, mas também o espacial. Já Alaôr Malta Guimarães também relaciona a história de Campinas aos grandes feitos dos Bandeirantes e, seguindo pelas fundações das instituições, mostra uma Campinas grandiosa que viria a se fundada a partir de 1773.

Júlio Mariano vai retomar a primeira comemoração do bicentenário para entrar no debate. Para ele, a celebração da data de 1739 não se referiu à fundação da cidade, mas sim a uma data simbólica. Porém, a controvérsia gerada pelo o Instituto Histórico e Geográfico de São Paulo acabou por transformar a questão numa polêmica sobre a fundação da cidade. Sua postura sobre a fundação não era a de encontrar a data exata, pois isso seria impossivel, mas de pensar como se veio a fundar a cidade, sempre pensando a história local à luz da história do Brasil, no caso, do Brasil colonial. Afirma que, na sua visão, Barreto Leme, no momento que chegou à região onde hoje se encontra Campinas, não tinha intenção de fundar uma cidade, nem tampouco um povoado. Quem realmente pensava em formar na região um povoado e em seguida uma freguesia seria Morgado Mateus. Este sim teria mais importância na fundação da cidade, sendo que Barreto Leme teria realizado sua ação apenas para cumprir ordens de Morgado. Mesmo assim, teria agido, possivelmente, contra sua própria vontade: "não é demais supormos que muito a contragosto recebeu Barreto Leme o titulo honorifico que lhe foi outorgado pelo Morgado Mateus que não era de meias-palavras, ordenava e não pedia." $25 \mathrm{O}$ ato de Morgado Mateus, considerado para ele como início do povoado urbano, é datado de 27 de maio de 1774, quando nomeia Barreto Leme diretor e fundador da nova povoação, e não 14 de julho, quando se realiza a primeira missa. Ele mesmo, no entanto, mostra que "na realidade, Campinas cidade veio a fundar-se definitivamente aos 14 dias de dezembro de 1797" ${ }^{26}$ como município Vila de São Carlos.

${ }^{25}$ MARIANO, Júlio. De como veio a fundar-se Campinas. Correio Popular, 20 nov. 1973.

${ }^{26}$ Idem, Campinas de ontem e anteontem. Campinas: ed. Maranata, 1970. 
Conforme dito acima, o debate foi paulatinamente perdendo interesse uma vez que a decisão oficial se consolidou. Contudo, o motivo mais importante está provavelmente ligado a outros fatores. Entre eles, podemos indicar o próprio crescimento de teses acadêmicas sobre a cidade como indicativo da substituição dos autodidatas pelos historiadores profissionais. A entrada dos historiadores profissionais em cena, já nos anos de 1980 e, mais expressivamente, nos anos $1990,{ }^{27}$ mudou o foco dos estudos e principalmente as concepções sobre o fazer historiográfico, quando questões sobre a data de fundação da cidade e outras da mesma natureza perderam completamente o sentido. Por outro lado, o próprio crescimento da cidade e sua metropolização nesse mesmo período ${ }^{28}$ provocou mudanças no próprio discurso oficial e no conteúdo e interesses da imprensa local. De qualquer maneira, uma manifestação extemporânea da controvérsia acabou acontecendo com a divulgação pela imprensa local dos resultados de uma tese de doutoramento do arquiteto Antônio da Costa Santos. ${ }^{29}$ Embora publicada em 2002, já em 1997 seu autor participara de uma série de reportagens, reafirmando o papel fundamental do Morgado de Mateus na fundação da cidade no contexto das reformas pombalinas, preocupadas então em garantir a pose das regiões da frente-sul da Colônia contra possiveis avanços dos espanhóis. ${ }^{30}$ No contexto atual, apenas um trabalho voltou ao tema, agora na tentativa de compreendê-lo a partir de fora do debate, analisando-o como um processo de "invenção de tradições". Mesmo aqui, no entanto, o autor parece querer tomar parti-

\footnotetext{
${ }^{27}$ Em um levantamento preliminar sobre os trabalhos acadêmicos (dissertações e teses) sobre Campinas realizado por mim em 2008, dos 51 trabalhos levantados, 28 foram realizados nos anos de 1990 . Na década anterior, apenas quatro foram feitos. A grande maioria (38) se concentrava na área de História Social.

28 Ver BAENINGER, Rosana. Espaço e tempo em Campinas: migrantes e expansão do pólo industrial paulista. Campinas: CMU/UNICAMP, 1996.

${ }^{29}$ SANTOS, Antônio da Costa. Campinas das origens ao futuro: Compra e venda de terra e água e um tombamento na primeira sesmaria da Freguesia de Nossa Senhora da Conceição das Campinas do Mato Grosso de Jundiaí (1739-1992). Ed. da Unicamp, Campinas: 2002.

${ }^{30}$ Conjunto de reportagens com Antônio da Costa Santos no Correio Popular, 16 a 20 de dezembro de 1997.
}

136 Revista de História Regional 16(1): 119-153, Verão, 2011 
do, contrapondo a visão de 1739, como mais expressiva de uma visão popular e acolhedora, à de 1774, supostamente mais elitista, com objetivo de valorizar a vocação moderna, religiosa e nobre da cidade. ${ }^{31}$

\section{Concepções presentes no debate: a critica.}

Observando as posições que tomaram os estudiosos sobre a fundação de Campinas, podemos perceber algumas temáticas e argumentos recorrentes em seus estudos. Assim, as principais contraposições entre aqueles que defendem a data de 1774 e aqueles que defendem uma data anterior parecem se diluir, uma vez que é possivel situá-los num cenário de concepções e valores bastante comuns. Em primeiro lugar, identificamos divergências sobre o marco de fundação que teria dado origem à cidade: o pouso, relativo a 1732 ou 1739, ou a Capela, relativo à freguesia de 1774. Isso teve como desdobramento o estabelecimento da contraposição entre a fundação real - algo dificil de definir quando ocorre - e a fundação oficial, relacionada à documentação escrita, como bem mostrou Odilon Nogueira de Mattos. No interior dessa controvérsia, a própria figura do fundador torna-se objeto de debate. Há um consenso entre os estudiosos em torno do nome de Barreto Leme, porém o debate concentra-se em torno da participação de Morgado Mateus, colocado em diferentes posições: como cofundador, como autor intelectual da fundação, ou em alguns momentos como vilão. Temos também autores que defendem a participação de outros personagens, como Frei Antônio de Pádua, a quem coube celebrar a primeira missa em 14 de julho de 1774.

Fazendo uma avaliação de conjunto, poderíamos propor que o conjunto dos escritos e autores mencionados acima, apesar de suas divergências, rivalidades, conflitos e controvérsias, pensava a história da cidade a partir de

${ }^{31}$ Ver nota 7. 
perspectivas e concepções bastante comuns em torno da função do passado e do modo correto de abordá-lo. O acordo tácito a respeito da relevância do problema - ou seja, a definição exata dos marcos fundadores da cidade pressupunha uma comunhão de interesses e visões a respeito do papel que o conhecimento do passado possuía numa determinada coletividade e como ele deve ser construído. Mais do que avaliar a coerência e fundamentação das diversas "teses" apresentadas, importa, sobretudo, retomar a questão enfocando não o problema da fundação em si, mas o debate que se construiu em torno dele. Debate este encarado como expressão da vigência de certas concepções de história e movimentos culturais que marcaram a vida de tantas cidades com características similares a de Campinas, ou seja, cidades que passaram por processos acelerados de transformação no modo como se inseriam nos circuitos da economia nacional e internacional, com impactos diretos em sua estrutura social e desdobramentos nas relações de poder correspondentes. Buscando um substrato comum, poderíamos dizer que as publicações que integram o debate resumido acima, tanto nos livros como nos artigos para os jornais locais, aproximam-se daquilo que Peter Burke chamou de um paradigma tradicional. Esse conceito pode ser definido por um conjunto de características no qual prevalece uma abordagem da sociedade que valoriza, sobretudo, suas dimensões político-institucionais; que preza a narrativa dos acontecimentos como estilo de escrita; que reflete um ponto de vista dos segmentos dominantes, mesmo quando fala dos grupos e manifestações populares; que supervaloriza os documentos escritos e oficiais como fontes legítimas de informação; que adota como modelo explicativo as declarações conscientes dos agentes; que ignora os condicionamentos sociais na construção do conhecimento e não incorpora as contribuições das Ciências Sociais na construção do conhecimento histórico. ${ }^{32}$ Assim, podemos perceber que os trabalhos dos autodidatas se concentram nos acontecimentos políticos da ocupação da região, numa

${ }^{32}$ Ver BURKE, Peter. A escrita da história. São Paulo: Unesp, 1992.

138 Revista de História Regional 16(1): 119-153, Verão, 2011 
perspectiva narrativa dos acontecimentos. Raramente notamos neles alguma análise dos aspectos econômicos, culturais ou sociais da região ou do País. Podemos observar a questão no seguinte trecho do artigo escrito por Celso Maria de Mello Pupo para o Correio Popular, "14 de julho de 1774 é pois data da fundação da Campinas Autônoma, Campinas Independente da Freguesia de Jundiaí da instituição política e religiosa". ${ }^{33}$ A própria forma como a história é apresentada é narrativa e objetiva, sem muita análise, não existindo a noção de processo em sua história. A história da fundação tornase também a história dos fundadores; é a fundação vista por cima, a fundação de Barreto Leme, de Morgado Mateus, conforme bem exposto no trecho a seguir: "O Morgado de Mateus, por uma orientação recebida da Coroa Portuguesa, aproveitou-se, para isso do desejo idealístico de Barreto Leme." ${ }^{34}$ História feita por documentos essencialmente escritos e oficiais, onde o documento é a história e é ele que afirma qual é a data verdadeira da fundação. Entretanto, estudiosos de posições diferentes sobre a fundação de Campinas, como Jolumá Brito e Celso Maria de Mello Pupo, analisando os mesmo documentos pertencentes ao livro do tombo, chegam a conclusões e datas da fundação distintas, sendo que ambos afirmam não existirem documentos que confirmem uma data de fundação diferente daquela defendida por eles. Nos escritos de Jolumá Brito fica bem claro a relação entre documento escrito e a história, como podemos observar no trecho a seguir: "Homem inteligente o Sr. Amaral reconhece a razão indiscutivel de documento que é história." 35

Contudo, a aproximação dos escritos campineiros dos anos 1960 e 1970 com aquilo que se define como concepção "tradicional" 36 pode ir mais longe. Por exemplo, essa

33 PUPO, Celso Maira de Melo. Fundação de Campinas. Correio Popular. Campinas, 29 ago. 1958.

${ }^{34}$ PUPO, Celso Maria de Melo. O Mérito da Fundação. Diário do Povo, Campinas, 28 jun. 1974.

${ }^{35}$ BRITO, Jolumá. Campinas, 247 anos. Diário do Povo, Campinas 7 jul. 1979.

36 Tradicional entendido aqui como um tipo de história elaborado antes 
preocupação quase obsessiva com a questão das origens, sugerindo quase uma hipnose, como diria Marc Bloch. A origem vista como momento em que estão depositados os elementos primordiais definidores da personalidade coletiva envolvente, definidor, portanto, da vocação verdadeira e legítima da cidade e de suas possibilidades de futuro. Em Introdução à História, ${ }^{37}$ Marc Bloch apontava as implicações e os equivocos decorrentes da adoração do ídolo das origens, característica marcante de muitos daqueles que se dedicavam ao estudo do passado. O autor apontava também a confusão frequente entre busca da origem de um determinado fenômeno e sua explicação causal. Embora Bloch certamente não compartilhasse da tese da autointeligibilidade do presente antes, pelo contrário, dedicava-se a demonstrar a falsidade dos seus postulados -, o fato é que via a história não como uma somatória de sobrevivências, mas principalmente com resultado de sua síntese dentro de condições históricosociais específicas. O problema real, portanto, não seria a mera identificação das origens, mas entender como os dados do passado foram incorporados no presente a partir das condições definidas por esse próprio presente. Isso tudo é muito interessante porque Bloch acaba nos dando elementos para pensarmos a própria emergência do debate acerca da fundação de Campinas nas décadas de 1950 e 1960, momento marcado por mudanças aceleradas na vida da cidade, cuja face mais visivel podia ser percebida na completa remodelação do centro histórico. A sequência de demolições de várias edificações, o alargamento das ruas e avenidas e a consequente perda de vários referenciais tidos então como importantes para a cidade. Somem-se a isso as transformações na economia da cidade decorrentes da instalação de várias empresas industriais. ${ }^{38}$ Acrescente-se a

das propostas de incorporação das contribuições das Ciências Sociais. Não compartilhamos do conteúdo pejorativo na maioria das vezes incorporado no termo.

${ }^{37} \mathrm{BLOCH}$, Marc. Introdução à História. Tradução Maria Manuel e Rui Grácio. 4. ed. Publicações Europa-América, s/d.

38 Já na década de 1940 instalaram-se na cidade a Sanbra, Anderson-Clayton, Swift, Matarazzo, entre outras. Nos anos 1950, instalaram-se a Singer do Brasil,

140 Revista de História Regional 16(1): 119-153, Verão, 2011 
isso o impacto causado pela chegada de levas de imigrantes vindos de várias regiões do Brasil, mas principalmente do interior do estado de São Paulo, do Paraná e de Minas Gerais. ${ }^{39}$ A adoração do ídolo das origens não surgiria então como mais uma das expressões das vertigens causadas pela modernização acelerada? Espécie de compensação ou reatamento imaginário causado pelo incômodo sentimento de distanciamento e perda dos referenciais coletivos. Decorre daí a busca de uma essência comum, pura na sua gênese. Nesse sentido, a busca do passado e a definição exata da fundação da comunidade contraditoriamente implicam na abolição de sua própria dimensão histórica. A cidade é retirada da história e transformada num dado da natureza. É como se ela sempre tivesse existido. A busca da origem traduz o entendimento de que o trabalho daqueles que estudam o passado concentrase no esforço de restituição dos elementos definidores da comunidade na sua integralidade. Ao buscarem a origem, estão buscando uma imagem e identidade da cidade atual, uma identidade que eles desejaram que fosse ressaltada. Nesse ponto, a busca da origem da cidade seria o bastante para forjar a imagem desejada. Mais do que isso, a narrativa mítica, conforme ressalta bem Marilena Chauí num estudo sobre o mito fundador do Brasil, é uma forma de resolver, no plano do imaginário, conflitos e contradições que não encontram soluções viáveis no plano da realidade social. A suspensão da historicidade do social operada pelo mito distorce a percepção da realidade, impedindo que ela seja equacionada racionalmente. Afirma Chauí:

O mito fundador oferece um repertório inicial de representações da realidade e, em cada momento da formação his-

Duratex, Pirelli, Hiplex. IBRAS/CBO, Bosch, General Electric, Rodhia. Ou então em cidades próximas, como no caso das empresas Chicago Bridge, Rigesa, Clark, Tema Terra, Wabco, 3M, IBM, entre outras. Ver BAENINGER, Rosana. Espaço e tempo em Campinas: migrantes e expansão do pólo industrial paulista. Campinas: CMU/UICAMP, 1996, p. 45.

39 Enquanto na década de 1950 a participação dos migrantes no crescimento populacional da cidade era de 41,5\%, a partir da década de 1960 passou a representar $62,5 \%$ e, nos anos $1970,63,4 \%$. Nesse período, a população da cidade passou de 152.540 para 664.559 habitantes. Ver BAENINGER, Rosana. op.cit., p. 53. 
tórica, esses elementos são reorganizados tanto do ponto de vista de sua hierarquia interna [...] como da ampliação de seu sentido [...] Assim, as ideologias, que necessariamente acompanham o movimento histórico da formação, alimentam-se das representações produzidas pela fundação, atualizando-as para adequá-las à nova quadra histórica. É exatamente por isso que, sob novas roupagens, o mito pode repetir-se indefinidamente. ${ }^{40}$

Assim, busca-se a origem em 1774 com a freguesia, embora seja defensável a crítica de que nesse caso há uma defesa ou construção de uma identidade muito mais urbana, planejada, moderna, nobre e religiosa da cidade, como pode ser bem observado no trecho a seguir:

[...] o fato é que o dia 14 de julho é o que melhor se ajusta para comemoração da fundação do núcleo urbano que em 198 anos se transformou na grande cidade de hoje, prestes a erigir-se em metrópole, em torno do qual gravitam 82 outros grandes centros urbanos, sedes de prósperos municípios. ${ }^{41}$

Enquanto aqueles que defendem datas anteriores, como 1732 ou 1739, estão em busca de uma origem mais popular, acolhedora e humilde: ${ }^{42}$

[...] Porque está ligada aos grandes feitos do bandeirismo paulista. É o lugar que por um determinismo histórico haveria de ser o assento do vilarejo, que, com o decorrer do tempo se transformaria na grandiosa metrópole interiorana do nosso estado. ${ }^{43}$

O fato é que, em ambas posições, é do mito de fundação que se trata. É nesse sentido que podemos considerar ainda que a concepção tradicional de história veiculada pelos autodidatas é uma concepção que, antes de se fundar

${ }^{40}$ CHAUÍ, Marilena. Brasil: o mito fundador e sociedade autoritária. São Paulo: Ed. Fundação Perseu Abramo, 2000, p. 10.

${ }^{41}$ PUPO, Barbosa. Por que 14 de Julho? Correio Popular, Campinas, 14 jul. 1972.

${ }^{42}$ Conforme insiste o trabalho já citado de Américo Vilella. Ver nota 7.

43 SEVÁ, Ataliba Amadeu. Um pouco da fundação de Campinas. Sociedade Brasileira de Artes Cultura e Ensino. Campinas: Biblioteca Pública Municipal de Campinas, s/d.

142 Revista de História Regional 16(1): 119-153, Verão, 2011 
no tempo, se estabelece em um espaço de experiência, como mostra Koselleck. Essa concepção, além disso, leva à formação ética e pedagógica da história, considerada mestra da vida, supondo uma crença de unidade essencial do gênero humano. A história é articulada com a tradição e a memória coletiva, uma associação na qual não se diferencia passado e presente, na qual o futuro se encontra no mais estrito controle. Nessa concepção de história, não está presente a ideia de processo, pois ela se comporta como uma série de exemplos e cenas sem articulação entre $\mathrm{si}^{44}$

O debate pode ainda ser encarado como exemplo daquilo que foi chamado de invenção das tradições. Nessa perspectiva teórica, o trabalho essencial é $A$ invenção das tradições, ${ }^{45}$ de Hobsbawm. Para ele, tradição inventada é o conjunto de práticas normalmente reguladas por regras ou abertamente aceitas. Tais práticas possuem natureza ritual ou simbólica que visa incluir certos valores e normas de comportamento através da repetição, sempre dando continuidade ao passado. A tradição é diferente do costume, das rotinas ou convenções, uma vez que fica ressaltado na tradição seu valor simbólico. Inventam-se novas tradições quando ocorrem transformações suficientemente amplas e rápidas tanto na demanda quanto na oferta da sociedade. Hobsbawm estabelece três tipos de "tradições inventadas" na era pós-Revolução Industrial. A primeira, que estabelece ou simboliza a coesão social ou as condições de admissão de um grupo ou de comunidades reais ou artificiais. Um segundo tipo, no qual as tradições inventadas estabelecem ou legitimam instituições, status ou relações de autoridade. E um terceiro, preocupado em garantir a socialização, a inculcação de ideias, sistema de valores e padrões de comportamento. No caso de nosso estudo, o debate da fundação de Campinas, pode-se dizer que esse envolveu a apropriação do primeiro e o último tipo de tradição inventada, principalmente o primeiro, que é o que trata a questão da criação de uma comunidade. ${ }^{46}$

\footnotetext{
${ }^{44}$ KOSELLECK, Reinhart. Futuro passado: contribuições à semântica dos tempos históricos. Rio de Janeiro: Ed. PUC Rio, 2006.

${ }^{45}$ HOBSBAWM, Eric J; RANGER, Terence (Org.). A invenção das tradições. Rio de Janeiro: Paz e Terra, 1984.

${ }^{46}$ A visão de Hobsbawm pode ser complementada por outro autor. Stephen Bann propõe, em As invenções da história, uma abordagem mais plural, em que as
} 
Esse conjunto de elementos apontados deve nos remeter à dimensão do modo como o poder se encontra instituído na sociedade e como, a partir disso, definem-se os critérios de reconstituição do passado. ${ }^{47}$ No caso do debate que estamos analisando, uma correlação importante deve ser apontada e que envolve exatamente essa dimensão do problema. Pois o período entre as décadas de 1940 e 1980 constitui um momento fundamental na história da cidade, interferindo nessa imagem elaborada pelos debates sobre a fundação. A crise do setor cafeeiro, assim como a falência de muitos fazendeiros e famílias tradicionais da cidade, foi superada pelo processo de industrialização que veio logo em seguida, sem uma interrupção significativa. Tal situação levou os setores agrários a lotearem suas propriedades e, nesse sentido, controlarem o processo de expansão urbana, que começava a ultrapassar a área reservada originalmente para a cidade. O sucesso dos empreendimentos imobiliários, entretanto, dependia do controle político da máquina pública. É justamente nesse momento que Campinas tornase uma das cidades mais atrativas do interior paulista pelos processos de migração interna. Assim, a elite campineira,

invenções da história estão presentes em um número quase infinito de instituições e representações. Bann admite uma pluralidade e uma heterogeneidade dessas invenções. Em segundo lugar para o autor, Hobsbawm trabalha a invenção das tradições considerando que a tradição incorpora uma falsa consciência, ou seja, foi inventada no sentido pejorativo do termo, surge do nada para propósitos meramente funcionais. Contra essa tradição inventada, os colaboradores do livro de Hobsbawm pressupõem um sentido correto da história, a partir do qual poderia se estabelecer o certo e o errado. No conjunto, esses ensaios representam o conhecimento histórico como último argumento capaz de desmistificar as invenções da tradição. Para Bann, o problema das invenções de tradições é que são menos prescritivas, como sugere Hobsbawm. A mudança estaria no tom de abordagem. Porém, o autor não nos oferece a resposta pra muitas questões levantadas por Hobsbawm: "Eu com certeza não tenho respostas para questão do consumo de massa contemporâneo de 'história' pela indústria da herança e de outros canais menos respeitáveis, exceto sugerir uma certa cautela ao criticá-lo e satirizá-lo." (p. 21)

${ }^{47}$ Há todo um conjunto de reflexões sobre esse tema que não aprofundaremos aqui, mas que pode ser consultado em: FONTANA, Josep. História: análise do passado e projeto social. Bauru/SP: Edusc, 1998; FERRO, Marc. A história vigiada. São Paulo: Martins Fontes, 1989; CLASTRES, Pierre. A sociedade contra o Estado. Rio de Janeiro: Francisco Alves, 1978, HOBSBAWM, Eric. O sentido do passado. In: Sobre a História. São Paulo: Companhia da Letras, 2000.

144 Revista de História Regional 16(1): 119-153, Verão, 2011 
inicialmente de extração agrária, supera a crise da economia exportadora em 1930. Trata-se, portanto, de uma elite que transitou da exploração de uma agricultura mercantil capitalista de exportação para a especulação imobiliária num contexto de expansão urbana e industrialização. A partir de 1930 a cidade cresceu sobre as áreas rurais, as antigas fazendas de café desmembradas sobre os efeitos da crise. Nesse contexto, estabelece-se uma articulação entre setores proprietários, especulação imobiliária, crescimento urbano e domínio político do poder municipal. ${ }^{48}$ É nesse momento que os recém-chegados, os migrantes, precisam ser informados sobre quem são os "donos" da cidade e integrados num esquema político em um papel previamente estabelecido. $\mathrm{O}$ recado é claro: aqueles que sempre mandaram porque criaram a cidade têm quase que o direito natural de continuarem mandando. No entanto, eles merecem isso não só por conta de sua antiguidade, mas também por constituírem uma elite moderna e modernizante, progressista. Sua história não demonstraria exatamente isso?

Resumindo os ingredientes apontados, teríamos então um processo razoavelmente ininterrupto de desenvolvimento econômico, que envolveu uma rede ampla de cidades, mas com certo destaque para Campinas; uma crise e remodelação urbana decorrente de uma conjuntura de epidemias, que marcou a cidade na virada do século XIX para o XX; superação da crise da economia exportadora, industrialização; expansão urbana e especulação imobiliária. A região de Campinas foi palco de um processo ininterrupto de desenvolvimento capitalista - desde sua incorporação nos circuitos da economia mundial no século XIX, até tornar-se um dos polos da industrialização nacional no século XX. Campinas não conheceu o ritmo de avanços e recuos por que passaram outras regiões, como o Nordeste e Minas Gerais. Em função disso, o progresso e a modernização acabaram se tornando critérios centrais de reconstituição da história da cidade. Os historiadores autodidatas foram profundamente marcados por esse ambiente. Incorporaram a ideia de progresso

$\overline{48}$ Ver SANTOS, Antônio da Costa, op. cit. Ver nota 4. 
acriticamente como lei geral que regia os destinos da região. Penso que esses elementos apontados forneceram para os memorialistas primeiro, e depois para todo um conjunto de teses acadêmicas inclusive, as orientações básicas de como a trajetória da cidade deveria ser reconstituída. Contribuíram na construção de um imaginário que, no limite, legitimou um processo de modernização de natureza capitalista e, articulado a isso, todo um contexto de especulação imobiliária e reprodução do capital fundiário urbano. Não deve ser ignorado aqui o papel da imprensa local nesse processo e seu esforço de constituir uma opinião pública a partir da opinião publicada. Não fosse a imprensa, as discussões e debates circulariam num âmbito bastante reduzido. Embora seja perceptivel um esforço de modernização dos jornais locais, como Correio Popular e Diário do Povo, ambos controlados por um mesmo grupo empresarial, nota-se um sentimento municipalista endêmico e intermitente, acirrado nos últimos anos no contexto de um processo crescente de metropolização na região de Campinas.

Um último comentário. É curioso observar que, apesar de todas as controvérsias mencionadas acima, no final da década de 1980 um prefeito local resolveu transferir as comemorações do aniversário da cidade, inclusive o feriado, de 14 de julho para o dia 8 de dezembro, Dia da Padroeira de Campinas. Até hoje vem sendo assim sem contestações significativas. O fato é que ambas as datas possuem um significado religioso, conforme vimos anteriormente. Num certo sentido, vislumbramos aqui a indicação da existência de uma linha interpretativa da história da cidade profundamente marcada por uma visão religiosa e providencial da realidade, mas que não emerge explicitamente como corrente interpretativa. Essa característica não é exclusiva de Campinas. Na realidade, surge como uma manifestação local de um imaginário político nacional. ${ }^{49} \mathrm{~A}$ ideia do mito de fundação está profundamente marcada por esse imaginário, que opera no nivel da sacralização da história, e no qual a mo-

\footnotetext{
${ }^{49}$ Ver mais uma vez as análises de Marilena Chauí no trabalho citado na nota 40 , p. $57-87$.
}

146 Revista de História Regional 16(1): 119-153, Verão, 2011 
dernização, o desenvolvimento, o progresso, surgem como manifestações laicizadas de uma história providencialista e salvífica. O documento abaixo é um texto publicado em um jornal campineiro, no início dos anos de 1950, pelo Cônego P. Quércia Sobrinho, que explicita aquela dimensão implícita nos autores que debateram sobre a fundação da cidade.

Campinas não escapou à sorte das origens das vilas e as cidades brasileiras.

Um grupo de casa e a sua poética e modesta ermida, consagrada à Virgem Nossa Senhora da Conceição.

Foi em derredor desse rústico padrão de fé que a povoação se desenvolveu e tornou-se o que hoje é, na pujança de sua grandeza material, a cidade líder do nosso "hinterland" paulista.

$[\ldots]$

Campinas, pelo apego ao seu torrão e pela têmpera moral de seus filhos, é a que mais se destaca na vanguarda das cidades do nosso Estado.

A seiva que lhe percorre as veias deflui de raízes profundas, agarradas ao solo fartamente amanhado pela crença religiosa.

Em derredor da capelinha, consagrada à Senhora da Conceição, é que se formou seu espírito religioso. O primitivo povoado, berço da grande cidade atual, em breve passou a Paróquia, como o nome de Campinas (Campos largos).

$[\ldots]$

Honra, pois, a Campinas e à crença que a embalou nos seus braços maternais, do seu berço humilde à pujança soberba do presente. Honra a seus filhos que, na seqüência de um evoluir por etapas florescentes e gloriosas, em todas elas jamais lhes faltaram o sal da terra e a luz do mundo a retemperar-lhes e a iluminar-lhes as jornadas, nas rotas escalonantes que buscam a grandeza e rumam para a glória [...] a religião de Jesus Cristo, a crença na imortalidade.

E a Vós, Senhora da Conceição, que vistes o nascer e o crescer deste grande povo e o amastes com ternura de Mãe [...] E assim como nos anos do passado fostes o alvo de suas fervorosas atenções, continuai a ser também, pelos anos do fu- 
turo, a mesma Mãe protetora e dedicada, a retraçar-lhe, sem quebra de sua fidelidade à Santa Igreja, a mesma trajetória feliz, nas sendas que aspiram seu crescer, avançar, subir, na marcha vitoriosa do progresso. ${ }^{50}$

\section{Retomando a questão sob outra perspectiva.}

Sendo assim, e a partir do conjunto de questões levantadas pelos autores acima, a retomada do problema da fundação de Campinas não implica na necessidade de tomarmos partido entre os autores e datas em questão: 1739 ou 1774. A discussão sobre as datas de fundação, os personagens fundadores, os locais em que a povoação teria começado, tudo isso se torna menos relevante na medida em que nos distanciamos do universo cultural e das concepções marcantes no interior das quais o debate foi desencadeado. Teríamos que recolocar o problema a partir de outra concepção de história e assim equacioná-lo de forma distinta.

Desse modo, podemos entender o debate da fundação de Campinas como decorrência das transformações que a sociedade campineira passava na época. A cidade recebia um alto fluxo migratório, o que suscitou nesses autores uma preocupação com uma suposta tradição perdida. Assim, esforçaram-se em escrever uma espécie de testamento cujo objetivo seria recuperá-la e recriar uma comunidade municipal que absorvesse esses novos grupos sociais, mas que deixasse bem claro quais eram as regras do jogo, ou seja, quem realmente mandava no âmbito municipal.

Por outro lado, a fundação de Campinas, ou de qualquer cidade, deve ser entendida não como uma ação individual de atores como Barreto Leme ou Morgado Mateus, ou então, em uma data especifica, quer seja o 14 de julho de 1774 ou não, como já dissemos anteriormente. Deve-se,

50 QUÉRCIA SOBRINHO, Cônego P. Retrospecto Religioso de Campinas, 1952. Disponivel em: <http://pro-memoria-de-campinas-sp.blogspot.com/2008/12/ personagem-dia-da-padroeira-de-campinas.html>., 25/04/2011.

148 Revista de História Regional 16(1): 119-153, Verão, 2011 
na verdade, partir da ideia de formação e não de fundação. Como chama atenção Chauí, a ideia de fundação vincula-se ao ponto originário que, embora atemporal, termina por atribuir sentido ao tempo, aparecendo simultaneamente como "emanado da sociedade" e "engendrando essa própria sociedade". Daí surgir como mito. Formação, por outro lado, associa-se aos processos temporais e históricos de estruturação e transformação da sociedade, na sua historicidade. Corresponde à história propriamente dita. ${ }^{51}$ Em outros termos, quando pensamos em fundação pensamos em origem. Formação nos coloca diante do problema da gênese estrutural dos fenômenos. Nesse sentido, o problema da formação deve ser equacionado a partir de outro plano da história, plano esse articulado com a dinâmica da história nacional e internacional, mais especificamente à sua inserção no circuito da economia internacional através das Políticas Pombalinas. Sem dúvida, como enfatizou Antônio da Costa Santos, o surgimento de Campinas relaciona-se com uma estratégia politica, dentro da qual varias vilas, povoados e freguesias foram fundadas com objetivos claramente geopoliticos. ${ }^{52}$

De qualquer maneira, deve-se levar em conta algumas dimensões básicas. Na segunda metade do século XVIII e início do XIX, a região de Campinas foi incorporada nos circuitos da economia mundial. Trata-se de um momento decisivo na história local, cuja dinâmica não pode mais ser entendida desconectada das circunstâncias externas. Foi cortada por uma estrada ou caminho que ligava a província de São Paulo ao Brasil Central (a chamada estrada dos Goiases); foi pisoteada pelas tropas de muares, lavrada por seus primeiros ocupantes, revolvida e explorada largamente por outros que vieram depois. A própria fundação e expansão da cidade resultaram dessas transformações, embora tenha sido igualmente um de seus vetores mais dinâmicos.

No entanto, entre a ocupação vagarosa, mas contínua, que se desenvolveu a partir do início do século XVIII

${ }^{51}$ CHAUÍ, op. cit., p. 10.

${ }^{52}$ SANTOS, Antônio da Costa, op.,cit., p. 37-38 
e aquela que se configurou no final desse período, apenas aparentemente transparece uma linha de continuidade ou processo cumulativo, natural, de adensamento demográfico e ocupação do solo. Resultam de uma análise mais profunda elementos de ruptura e descontinuidade. De fato, pode-se perceber nas últimas décadas do século uma alteração brusca e mesmo uma mudança de rumos no processo de desenvolvimento regional. Os deslocamentos mais evidentes surgem na implantação e depois substituição da lavoura do milho pela cana de açúcar e, posteriormente, pelas plantações de café; na chegada dos sesmeiros e na expansão das propriedades rurais em locais antes ocupados por pequenos sitiantes e lavradores nômades; na chegada de negros escravizados em quantidades crescentes onde antes predominava o trabalho do núcleo familiar e dos mutirões; na substituição das vendas e dos locais de pouso dos tropeiros pelos armazéns, casas de importações, casas bancárias, etc.

Falamos aqui em substituição, contudo, seríamos mais precisos se pensássemos em termos de sobreposição. Nem o milho, nem o sitiante, nem os mutirões e santos desapareceram repentinamente. Uma nova moldura os envolveu, um novo enquadramento, uma nova dinâmica econômica e social alterou certamente o seu sentido, suas funções e sua abrangência.

Para os padrões regionais, não se tratou de alterações econômicas e sociais simples, um novo ciclo econômico, o ingresso de novos personagens em cena e uma mudança na paisagem rural. Mais do que as transformações que afetaram cada uma das esferas que compõem a existência, a novidade estava principalmente num novo modo de articulação do econômico, do político, do religioso, etc. O elemento realmente novo, que possibilitou não apenas diferentes realidades locais, mas uma nova configuração geral da vida, foi a inserção definitiva e radical da região nos circuitos da economia mundial.

Temos aqui o enquadramento geral que articula o conjunto de características regionais e ao qual devemos atribuir uma função analítica. O impacto da nova ordem alterou de 
maneira profunda e irreversivel o modo de vida local. Esta nova ordem não se traduz apenas numa modificação econômica, embora implique um regime de propriedade da terra diferente, novas tecnologias e organização da produção, novas relações sociais nas atividades produtivas associadas a novos e coerentes mecanismos de expropriação daqueles que realizam o trabalho. Juntamente com esses elementos e garantindo as condições de sua reprodução durante períodos mais prolongados, definiram-se configurações sociais especificas e formas institucionais particulares, bem como visões de mundo e um imaginário histórico adequado.

\section{Considerações finais}

Nossa preocupação central voltou-se, em primeiro lugar, para a definição de critérios básicos a partir dos quais pudéssemos avaliar a produção histórica que se desenvolveu antes e fora dos muros da universidade. Frequentemente, mas não de maneira absoluta, tais escritos caracterizam-se por enfeixar orientações muitas vezes incompativeis oriundas da ciência histórica formalizada, do memorialismo afetivo, das regras da erudição, do antiquarismo, etc. Esforçamo-nos em analisar esses escritos não propriamente como um estudo sobre a história da cidade, mas, sobretudo, como uma expressão de um momento particular dessa história. Isso não significa desconsiderar sua importância para a compreensão da história, nem tampouco minimizar a relevância do problema específico da fundação da cidade, bem como de outras questões e temas aos quais tal historiografia se dedicou. Significa, no entanto, que uma avaliação mais precisa dessa produção faz-se necessária caso não queiramos correr o risco de reproduzir seus mitos. Mesmo o problema da fundação, entendemos que deva ser reavaliado a partir de outra perspectiva teórica e não descartado simplesmente. Por fim, nossa compreensão é a de que o caso da cidade de Campinas pode ser generalizado para outras cidades paulistas. Princi- 
palmente aquelas criadas ou que prosperaram a partir do período cafeeiro, ou seja, durante a segunda metade do século XIX e a primeira do XX. Entretanto, o período cafeeiro não foi homogêneo e, em sua expansão pelo interior do estado de São Paulo, podemos encontrar várias especificidades. Sendo assim, as conclusões que alcançamos com o presente estudo devem ser confrontadas com as trajetórias e experiências de outras cidades, visando confirmar características comuns, bem como combinações únicas dos elementos e componentes identificados em Campinas.

Resumo: Campinas comemorou seu bicentenário de fundação em dois momentos: 1939 e 1974. A primeira ocasião coincidiu com o Estado Novo e, a segunda, com a Ditadura Militar. A definição da data oficial de fundação da cidade foi objeto de uma polêmica entre jornalistas e estudiosos da história local que ocupou as páginas dos jornais no início dos anos de 1970, com repercussões nos debates na Câmara Municipal e em todas as instituições voltadas para a preservação da memória municipal. Essa escrita da história foi realizada por estudiosos autodidatas e compõe um conjunto de escritos com características híbridas, nos quais gêneros diversos se misturam. O objetivo deste estudo é reconstituir esse debate e analisar as concepções de história implícitas nele, bem como seu impacto na construção de uma identidade municipal e as relações de poder nesse âmbito municipal.

Palavras-chave: Historiografia. Campinas. Memória.

Abstract: Campinas commemorated its bicentennial of foundation at two moments: 1939 and 1974. The first occasion coincided with the New State, and second with the Military dictatorship. The definition of the official date of foundation of the city was object of a controversy between studious journalists and of the local history that the pages of periodicals of the years of 1970 with repercussions in the debates in the City council and all had occupied at the beginning the

152 Revista de História Regional 16(1): 119-153, Verão, 2011 
institutions come back toward the preservation of the municipal memory. This writing of history was carried through by studious self-taughts person, and composes a set of writings with hybrid characteristics, where diverse sorts if mix the objective of the study are to reconstitute this debate and to analyze the implicit conceptions of history in it, as well as its impact in the construction of a municipal identity and the relations of being able in this municipal scope

Keywords: Historiografy, Campinas, memory

Artigo recebido para publicação em 01/09/2010

Artigo aprovado para publicação em 27/04/2011 